University of Nebraska - Lincoln

DigitalCommons@University of Nebraska - Lincoln

USDA Forest Service / UNL Faculty Publications U.S. Department of Agriculture: Forest Service --

National Agroforestry Center

2007

\title{
Development and analysis of a 12-year daily 1-km forest fire dataset across North America from NOAA/AVHRR data
}

\author{
Ruiliang Pu \\ University of Maryland \\ Zhanqing Li \\ University of Maryland, zli@atmos.umd.edu \\ Peng Gong \\ University of California - Berkeley \\ Ivan Csiszar \\ University of Maryland \\ Robert Fraser \\ Canada Center for Remote Sensing \\ See next page for additional authors
}

Follow this and additional works at: https://digitalcommons.unl.edu/usdafsfacpub

Part of the Forest Sciences Commons

Pu, Ruiliang; Li, Zhanqing; Gong, Peng; Csiszar, Ivan; Fraser, Robert; Hao, Wei-Min; Kondragunta, Shobha; and Weng, Fuzhong, "Development and analysis of a 12-year daily 1-km forest fire dataset across North America from NOAA/AVHRR data" (2007). USDA Forest Service / UNL Faculty Publications. 168.

https://digitalcommons.unl.edu/usdafsfacpub/168

This Article is brought to you for free and open access by the U.S. Department of Agriculture: Forest Service -National Agroforestry Center at DigitalCommons@University of Nebraska - Lincoln. It has been accepted for inclusion in USDA Forest Service / UNL Faculty Publications by an authorized administrator of DigitalCommons@University of Nebraska - Lincoln. 


\section{Authors}

Ruiliang Pu, Zhanqing Li, Peng Gong, Ivan Csiszar, Robert Fraser, Wei-Min Hao, Shobha Kondragunta, and Fuzhong Weng 


\title{
Development and analysis of a 12-year daily 1-km forest fire dataset across North America from NOAA/AVHRR data
}

\author{
Ruiliang $\mathrm{Pu}^{\mathrm{a}, \mathrm{b}, 1}$, Zhanqing $\mathrm{Li}^{\mathrm{a}}{ }^{\text {,* }}$, Peng Gong ${ }^{\mathrm{c}}$, Ivan Csiszar ${ }^{\mathrm{d}}$, Robert Fraser ${ }^{\mathrm{e}}$, \\ Wei-Min Hao ${ }^{f}$, Shobha Kondragunta ${ }^{g}$, Fuzhong Weng ${ }^{g}$ \\ ${ }^{a}$ Earth System Science Interdisciplinary Center, University of Maryland, College Park, MD 20742, United States \\ ${ }^{\mathrm{b}}$ State Key Lab of Remote Sensing Science, IRSA, Box 9718, Beijing, 100101, China \\ ${ }^{\mathrm{c}}$ Center for Assessment and Monitoring of Forest and Environmental Resources, University of California, Berkeley, CA 74720, United States \\ ${ }^{\mathrm{d}}$ Department of Geography, University of Maryland, College Park, MD 20742, United States \\ e Canada Center for Remote Sensing, Ottawa, Canada K1A 0Y7 \\ ${ }^{\mathrm{f}}$ USDA Forest Service, Fire Sciences Laboratory, P.O. Box 8089, Missoula, MT 59807, United States \\ ${ }^{g}$ NOAA/NESDIS Office of Research and Applications, Camps Spring, MD 20746, United States
}

Received 11 November 2005; received in revised form 2 February 2006; accepted 26 February 2006

\begin{abstract}
Fires in boreal and temperate forests play a significant role in the global carbon cycle. While forest fires in North America (NA) have been surveyed extensively by U.S. and Canadian forest services, most fire records are limited to seasonal statistics without information on temporal evolution and spatial expansion. Such dynamic information is crucial for modeling fire emissions. Using the daily Advanced Very High Resolution Radiometer (AVHRR) data archived from 1989 to 2000, an extensive and consistent fire product was developed across the entire NA forest regions on a daily basis at 1-km resolution. The product was generated following data calibration, geo-referencing, and the application of an active fire detection algorithm and a burned area mapping algorithm. The spatial-temporal variation of forest fire in NA is analyzed in terms of (1) annual and monthly patterns of fire occurrences in different eco-domains, (2) the influence of topographic factors (elevation zones, aspect classes, and slope classes), and (3) major forest types and eco-regions in NA. It was found that 1) among the 12 years analyzed, 1989 and 1995 were the most severe fire years in NA; 2) the majority of burning occurred during June-July and in low elevation zones $(<500 \mathrm{~m})$ with gentle slopes $\left(<10^{\circ}\right)$, except in the dry eco-domain where more fires occurred in higher elevation zones $\left.(>2000 \mathrm{~m}) ; 3\right)$ most fires occurred in the polar ecodomain, sub-arctic eco-division, and in the taiga ( boreal forests), forest-tundras and open woodlands eco-provinces in the boreal forests of Canada. The tendency for multiple burns to occur increases with elevation and slope until about $2500 \mathrm{~m}$ elevation and $24^{\circ}$ slope, and decreases therefore. In comparison with ground observations, the omission and commission errors are on the order of $20 \%$.
\end{abstract}

(C) 2006 Elsevier Inc. All rights reserved.

Keywords: Forest fires; Burned area mapping; NOAA/AVHRR data; North America

\section{Introduction}

Wildfires play a critical role for many biomes in controlling successional patterns, primary productivity, and carbon cycling (Beringer et al., 2003; French et al., 1996; Isaev et al., 2002; Kasischke \& Bruhwiler, 2003; Qi \& Gong, 1996). Forest fires

\footnotetext{
* Corresponding author.

E-mail address: zli@atmos.umd.edu (Z. Li).

${ }^{1}$ Current address: Department of Geography, University of South Florida, Tampa, FL 33620, United States.
}

are usually extensive and hot, liberating vast amounts of carbon and other trace gases into the atmosphere (Beringer et al., 2003). At present, the poor knowledge on the amount of carbon released from forest fires is one of the major uncertainties in determining whether boreal forests serve as a sink or source in the global carbon cycle (Fung, 1996; Isaev et al., 2002; Kurz \& Apps, 1996; Tans et al., 1990). Quantification of fire emissions such as $\mathrm{CO}_{2}, \mathrm{CO}, \mathrm{CH}_{4}, \mathrm{PM} 2.5$ (particulate matter $<2.5 \mu \mathrm{m}$ in diameter) and PM10 (particulate matter $<10 \mu \mathrm{m}$ in diameter) requires accurate measurements of fuel consumption and burned area (Li et al., 2006). 
To date, most studies concerning fire activity and its impact on land cover (LC) have focused on tropical zones (e.g., Bowman et al., 2003; Brivio et al., 2003; Fisher et al., 2003; Hao et al., 1996; Justice et al., 1996, 2003; Kaufman et al., 1990b, 1994, 1990a; Morisette et al., 2005; Ward et al., 1996). Although fire activity in the boreal and temperate ecosystems is not as widespread as in tropical ecosystems, its impact on land cover lasts longer due to slow growth rates. The succession of boreal and temperate forests makes land cover change following fires more complex and dynamic, which is characterized by successive cohorts of hardwood, mixedwood, and softwood dominance. North America's (NA) boreal and temperate forests are primarily found in Canada and the U.S. The total forested area in the two countries is approximately 7.33 million $\mathrm{km}^{2}$ (733 million ha) or over $17 \%$ of the world's forestland, which occupies $45 \%$ and $32 \%$ of the Canadian and U.S. territories, respectively. Fires burn an average of $24,000 \mathrm{~km}^{2}$ (2.4 million ha) of boreal forests annually (Li et al., 2000a) in Canada and $11,000 \mathrm{~km}^{2}$ (1.1 million ha) of forestland in the U.S. (http://www.nifc.gov/fireinfo). Although annual fire point databases are available in the U.S. and Canada, detailed information concerning the spatial distribution and temporal variation of fires is still lacking, but the situation is being improved recently thanks to the efforts of U.S. federal agencies and other institutes. For example, a fire dataset with an inquiry system was developed by the U.S. Bureau of Land Management based on fire data collected by five U.S. federal agencies. The dataset has been used for analyze spatial and temporal variability of fires (e.g., Liu, 2004; Westerling et al., 2003). Development and analysis of a time series of burned areas in forests would help elucidate the relation and interaction between fire activities and climate change (Weber \& Stocks, 1998).

Climate, vegetation, and fire are interrelated so that a change in any of the variables can affect the others. Climate change directly and indirectly influences the wildfire regime through various mechanisms. Fire potential is directly linked to weather conditions favorable for fire ignition by lightning. Climate change may alter the structure and composition of plant communities and thus affect the physical and chemical properties of fuels. Conversely, fire activities can influence climate change by emitting both greenhouse gases and aerosol particles. To unravel the complex relationship, a long-term coherent wild fire dataset is essential.

Considering the remoteness and vast extent of the boreal and temperate biomes, satellite remote sensing is particularly suited for monitoring fire activity. Many different satellite sensors, with complementary capabilities, have been employed for fire studies. The MODerate resolution Imaging Spectroradiometer (MODIS) possesses the most useful channels for fire monitoring and mapping but has the shortest history and has insufficient temporal sampling (e.g., Justice et al., 2002; Kaufman et al., 2003, 1998). The Geostationary Operational Environmental Satellite (GOES) provides the most frequent observations but has the least channels at a coarser resolution and poor coverage at high-latitudes (e.g., Prins \& Menzel, 1990). The Advanced Very High Resolution Radiometer (AVHRR) on board the National Oceanic and Atmospheric Administration's (NOAA) polar orbiting satellites has been most widely used due to its long history and acceptable capability (Dwyer et al., 1999; Flannigan \& Vonder Haar, 1986; Justice et al., 1996; Kaufman et al., 1990a; Li et al., 1997; Pu et al., 2004), but this instrument also suffers from numerous inherent limitations (Li et al., 2001).

To exploit the long historical archive at a spatial resolution suitable for regional-scale studies, we processed daily AVHRR $1-\mathrm{km}$ datasets covering most of the NA continent and developed a coherent long-term forest fire inventory over a period of 12 years (May through October from 1989 to 2000). This paper will focus on analysis of the spatial and temporal variations of burn scars during fire seasons. Specifically, we analyzed interannual and intra-annual fire variability over four major forest types and three eco-regions (polar, humid temperate, and dry eco-regions), with different topographic factors (elevation zones, aspect and slope classes), as well as fire reoccurrence. Datasets used are described in Section 2. Section 3 describes the data processing system, algorithms, and analysis methodology. In Sections 4 and 5, the algorithms are validated against ground observations and the fire data are analyzed. Concluding remarks are given in the last section.

\section{Data sets}

\subsection{NOAA/AVHRR}

AVHRR data acquired by two NOAA polar orbiting satellites (NOAA-11 and NOAA-14) were employed to generate the fire history over NA for the period May 1 to October 31 in each year from 1989 to 2000 (except for 1994 when the period analyzed was May 1 to September 13). The AVHRR data for 1994 were received from the Canada Centre for Remote Sensing and all other AVHRR data were downloaded from the NOAA Satellite Active Archive (SAA: http:/www.saa.noaa. gov). The SAA is now replaced with NOAA Comprehensive Large Array-data Stewardship System (CLASS) database (http://www.class.noaa.gov). All AVHRR data were acquired in the afternoon with the local crossing time ranging from 12:00 to 16:00. There are two types of NOAA/AVHRR datasets collected at full resolution (nominally $1-\mathrm{km}$ ), namely, the Local Area Coverage (LAC), and High Resolution Picture Transmission (HRPT). LAC data are recorded onboard the satellite and downloaded at two NOAA receiving stations and archived at the NOAA SAA. The SAA LAC data date back to May 1985. Over NA, however, most of the 1-km data in the NOAA archive are from the HRPT receiving stations. The HRPT data are supplemented by LAC data for regions outside the acquisition area of the HRPT stations.

\subsection{Topography}

Topographic data were extracted from the GTOPO30 Global Digital Elevation Model (DEM), providing a spatial resolution of $30^{\prime \prime}$ in latitude and longitude, and produced by the United States Geological Survey (USGS) at the Earth Resources Observation Systems (EROS) Data Center (EDC) (http://edcdaac. usgs.gov/gtopo30/gtopo30.html). The data were resampled to $1 \mathrm{~km}$ in both latitude and longitude before geocoding and 
Table 1

1996 burned area (May-Oct.), mapped by HANDS from AVHRR data, was validated with the NFOD (National Fire Occurrence Database) point database

\begin{tabular}{|c|c|c|}
\hline May-Oct., 1996 & Burned area $\left(\mathrm{km}^{2}\right) /$ fires & Percentage $(\%)$ \\
\hline \multicolumn{3}{|c|}{ Burned area mapped by AVHRR checked with NFOD: } \\
\hline True burning & 9067 & 79 \\
\hline False fires & 2406 & 21 \\
\hline Total & 11,473 & 100 \\
\hline May-Oct., 1996 & Number of fires & Percentage $(\%)$ \\
\hline \multicolumn{3}{|c|}{ Number of fires detected by AVHRR checked with NFOD: } \\
\hline True fires & 192 & 73 \\
\hline False fires & 71 & 27 \\
\hline Total & 263 & 100 \\
\hline \multicolumn{3}{|c|}{ Fires (points) recorded from NFOD detected by AVHRR: } \\
\hline Detected by AVHRR & 61 & 84 \\
\hline Omitted by AVHRR & 12 & 16 \\
\hline Total & 73 & 100 \\
\hline
\end{tabular}

extraction of topographic factors. The DEM data are needed for geocoding, which incorporates terrain corrections to produce ortho-rectified products. They are also used to compute the terrain aspect and slope. Elevation was divided into 4 zones for fire pattern analysis: elevation $\leq 500 \mathrm{~m}, 501-1000 \mathrm{~m}, 1001-$ $2000 \mathrm{~m}$, and $>2000 \mathrm{~m}$. The terrain aspect was classified into 9 classes: N (north), NE (northeast), E (east), SE (southeast), S (south), SW (southwest), W (west), NW (northwest) and flat, based on a general aspect classification method ( $c f$. Kasischke et al., 2002; Rollins et al., 2002). Slope was classified into 3 classes for a similar gross pattern analysis: $\leq 10^{\circ}, 10^{\circ}-20^{\circ}$, and $>20^{\circ}$, and is divided into $2^{\circ}$ intervals for analyzing the patterns of multiple burning.

Topography may influence fire occurrence and spread on landscape to regional scales (Agee, 1993). Particularly, elevation affects the temperature and water availability. In mountainous areas, elevation also influences the potential for ignition of fires by lightning (Fuquay et al., 1979). Terrain aspect directly affects fuel moisture status by altering the solar insolation (Waring \& Running, 1998), while the slope angle affects fire spread by increasing the efficiency of radiant energy transfer from flaming fronts to upslope fuels (Agee, 1993). A fire spreading up a steep slope resembles a fire spreading under the influence of a strong wind (Brown \& Davis, 1973).

\subsection{Land cover types and eco-regions}

The USGS's EDC, University of Nebraska-Lincoln, and Joint Research Centre of the European Commission jointly produced a 1-km resolution Global Land Cover Characteristics Data Base for use in a wide variety of environmental research and modeling applications (Loveland et al., 2000). The land cover product for this study was edited by merging the 17-class International Geosphere-Biosphere Programme-Data and Information System (IGBP-DIS) land cover legend from the Global Land Cover Characteristics Data Base (GLCDB:http:// edcdaac.usgs.gov/glcc/globdoc2_0.asp). The land cover map contains 10 classes: water, mixed forest, deciduous forest, transitional forest, coniferous forest, arctic/alpine tundra, barren lands, agricultural cropland, rangeland and pasture, and cities. Our analyses are limited to four forest types: mixed forest, deciduous forest, transitional forest and coniferous forest.

The eco-region map compiled by Bailey (1998) over NA is also used in this study. It identifies ecosystem regions at a continental scale based on macroclimate. Macroclimate is among the most significant factors affecting the distribution of life on Earth (Bailey, 1998). Bailey (1998) subdivided the continent into eco-regions with three levels of detail based on macroclimatic conditions and on the prevailing plant formations determined by those conditions. The broadest level concerns domains related to climate: polar, humid temperate, and dry and humid tropical in NA. Within these domains are 15 divisions plus mountain divisions with altitudinal zonation.

\section{Algorithms and processing procedure}

The Geocomp-N satellite data processing and retrieval system (Cihlar et al., 2002) was used to geocode and composite daily NOAA/AVHRR data. In the geocoding stage, radiometric correction and calibration and spatial geometric corrections are conducted on data in 5 AVHRR channels using a calibration auxiliary file, an orbit parameter file, as well as georeferenced chip images. Calibration for visible (Ch1) and near-IR (Ch2) measurements employs time-dependent offset and gain values recommended by Rao and Chen (1996). The thermal AVHRR channels (Ch3-5) are calibrated using an onboard blackbody reference. The original AVHRR data, having a variable pixel size, were re-sampled to a constant $1-\mathrm{km}$ resolution. NA-wide composites are registered to the Lambert Conformal Conic projection using an orbital model and high-resolution Landsat Thematic Mapper image chips. Typically, the accuracy of pixel location registered using the image chips is better than $1 \mathrm{~km}$ but varies with the density of image chips. The outputs from this stage are reflectance at the top of atmosphere from channels 1 and 2 and brightness temperature (in degrees Kelvin) from channels $3-5$. In the compositing stage, images acquired in different satellite orbits are combined into one image based on a criterion of minimum satellite zenith angle in the overlapped areas of the images.

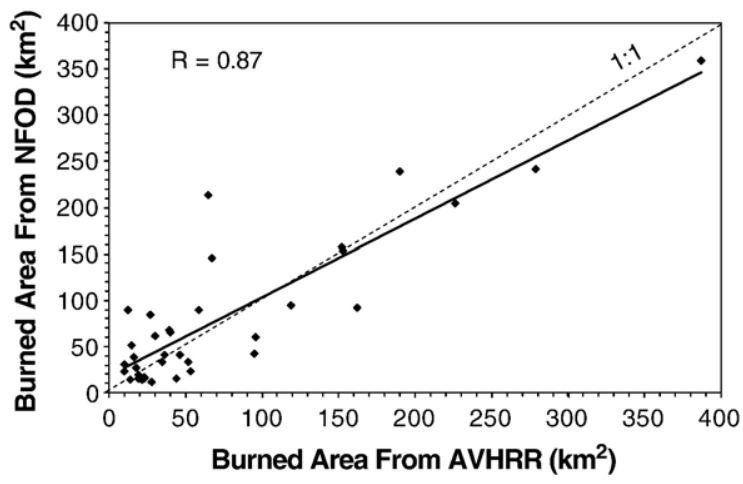

Fig. 1. Comparison of burned areas detected from AVHRR and from the National Fire Occurrence Database. 


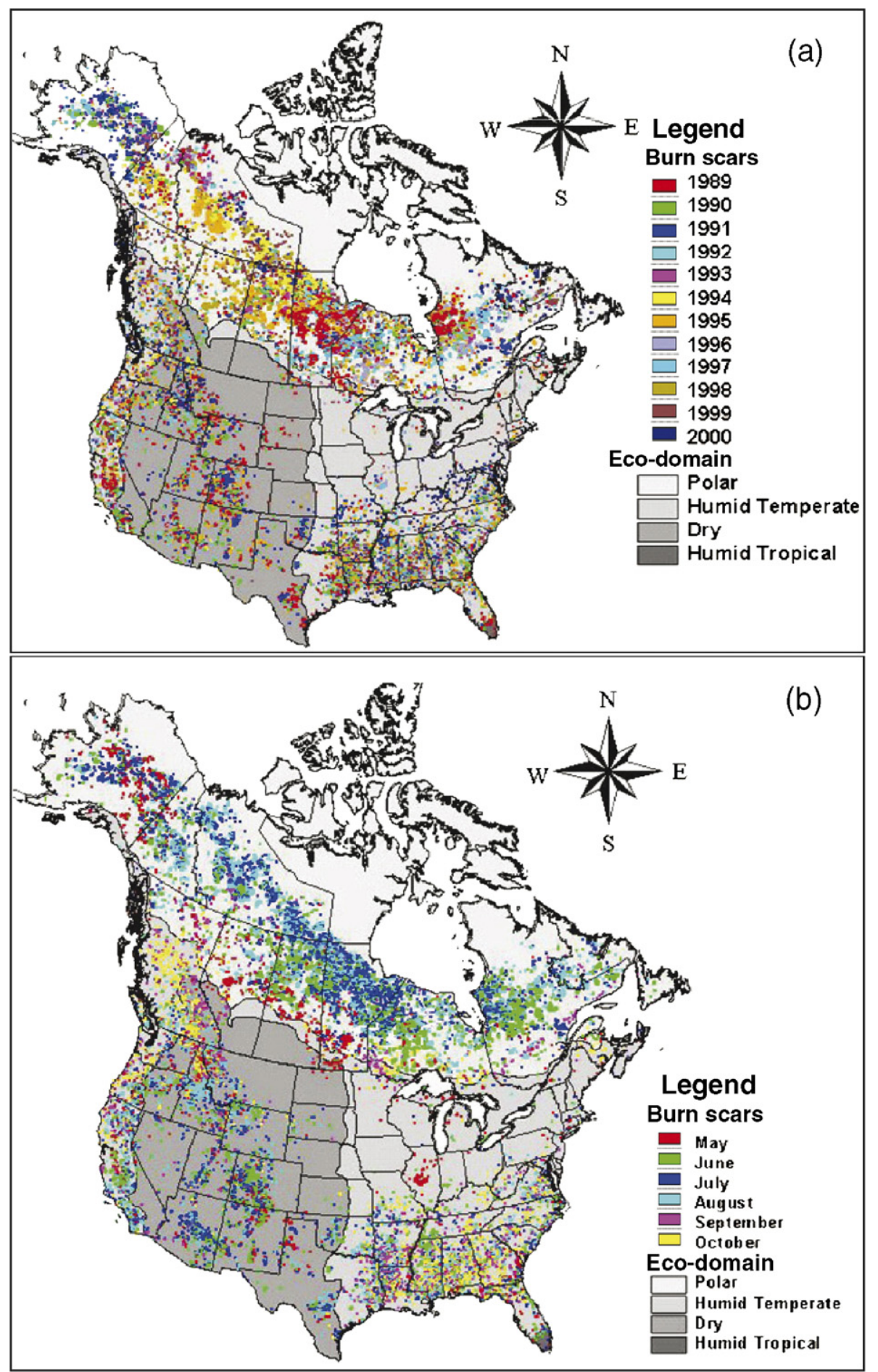

Fig. 2. 12-year burn scar distribution over forested areas in the U.S. and Canada with different color legends denoting the year (a) and month (b) overlying 4 eco-domains.

All daily active fires in a fire season from 1989 to 2000 were detected using a modified version of the algorithm ( $\mathrm{Li}$ et al., 2003) that was originally developed by Li et al. (2000a) for application in Canada using NOAA-14 data only. It consists of a series of threshold tests to identify potential fire pixels and eliminate false alarms. A few minor modifications were introduced to improve the detection accuracy in the U.S. (Li et al., 2003). The modified version reduces the commission error when applied over the entire NA continent. Since hot spots can be detected only under clear-sky conditions, they constitute a portion of the total burned area and the omission error depends on the frequency of cloud cover and satellite overpasses ( $\mathrm{Li}$ et al., 2000b; Pu et al., 2004), which can be overcome by mapping burned areas.

A hybrid burn mapping method, dubbed Hotspot and NDVI Differencing Synergy (HANDS), was used in our study, and the 
(a)

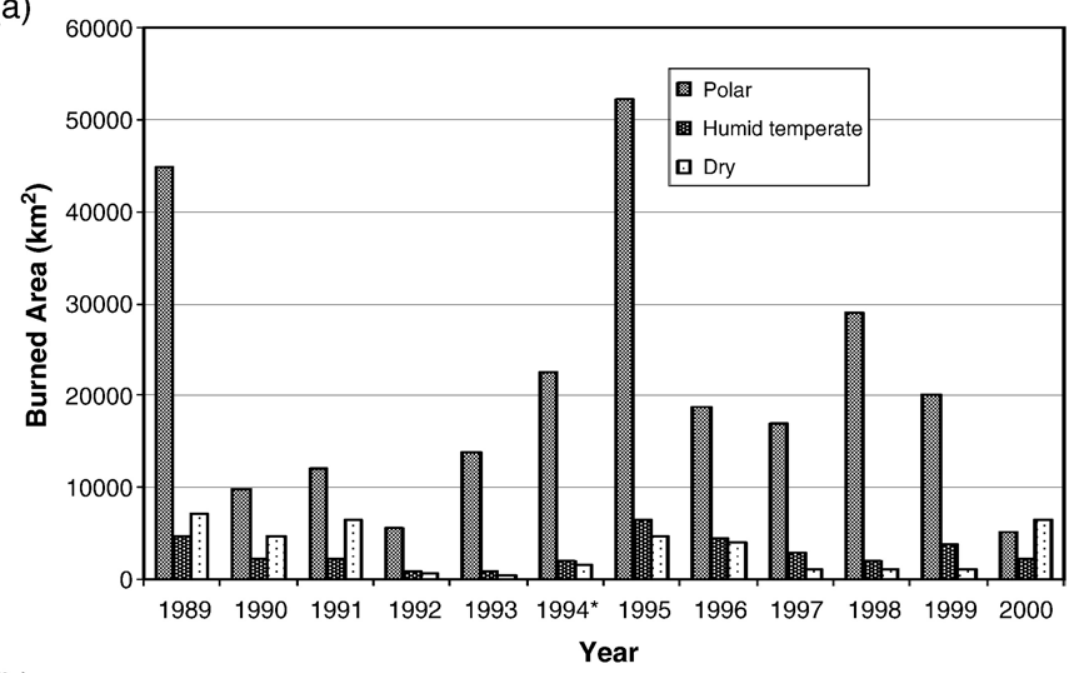

(b)

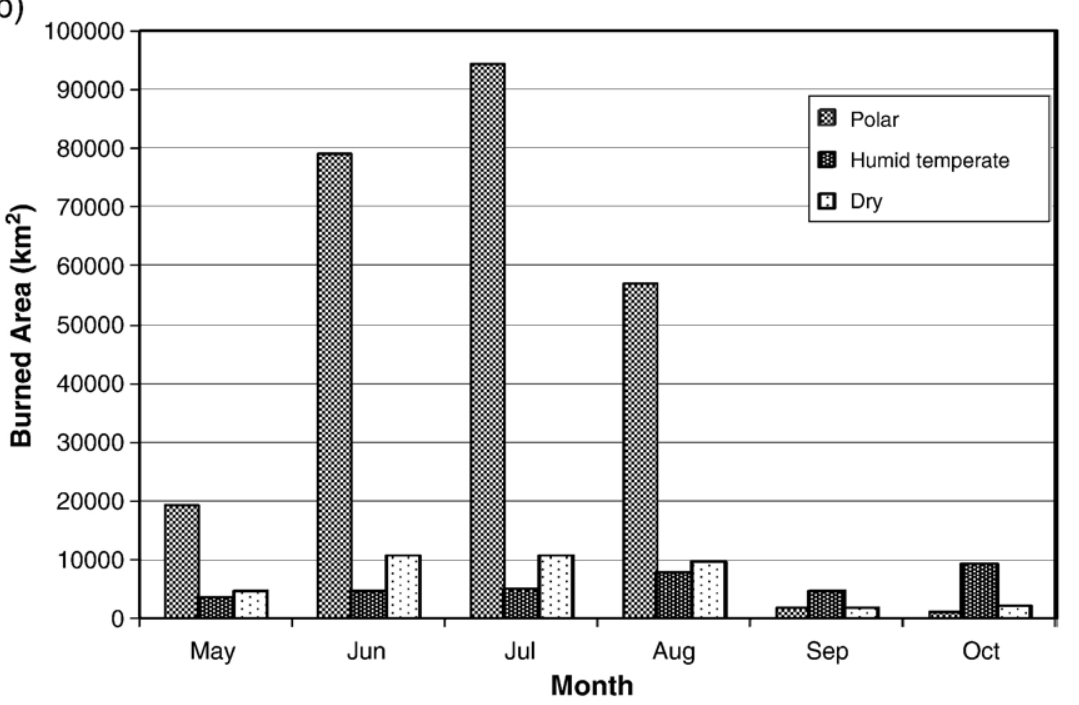

Fig. 3. Total burned areas in different years (a) and months (b) differentiated by the 3 eco-domains.

major features are described as follows (Fraser et al., 2000). The algorithm takes advantage of both hotspot detection and changes in NDVI (or other vegetation index) before and after burning. First, the detected hotspots are confirmed as real fires if there are significant decreases in NDVI in the subsequent year. Second, the NDVI difference statistics (mean and standard deviation) are computed from the confirmed active fires and are used to identify potential burned pixels. Third, regional thresholds are executed to reclaim the missing burned pixels. Finally, pixels passing regional thresholds are connected to create burned scar patches. Any burned patches that contain less than $5 \%$ of confirmed hotspot pixels are removed because, for this case, we assume that the NDVI decrease is caused by other factors, such as seasonal vegetation senescence, drought timber harvesting, image misregistration, and cloud contamination. The method has been extensively validated (Fraser et al., 2004; Fraser \& Li, 2002).

After the AVHRR data were geocoded and composited, the modified active fire detection algorithm ( $\mathrm{Li}$ et al., 2003, 2000a) was first applied to detect hotspots from daily AVHRR data throughout the 1989-2000 fire seasons. The hotspots and NDVI maximum values obtained for the same month but in two consecutive years (for yearly or seasonal burn scar mapping) or two consecutive months (for monthly burn scar mapping) were composited and the HANDS algorithm (Fraser et al., 2000) was applied. Monthly burned areas were computed from May through October and were accumulated to obtain yearly burned areas. Burn scar results for the 6 months across the 12 years (1989-2000) were obtained except for 1994 where burn scar results for May through August were included.

\section{Validation}

The active fire detection algorithm of Li et al. (2000a) was originally developed for application to NOAA-14 data in Canada. Before applying it to NOAA-11 (1989-1994) data in NA, the algorithm was tested using data from 3 different years (1989, 1991 and 1993) in different locations (Manitoba, Saskatchewan, Northwest Territories, and Ontario) in Canada. The detection results agree well with the ground-based fire reports generated 


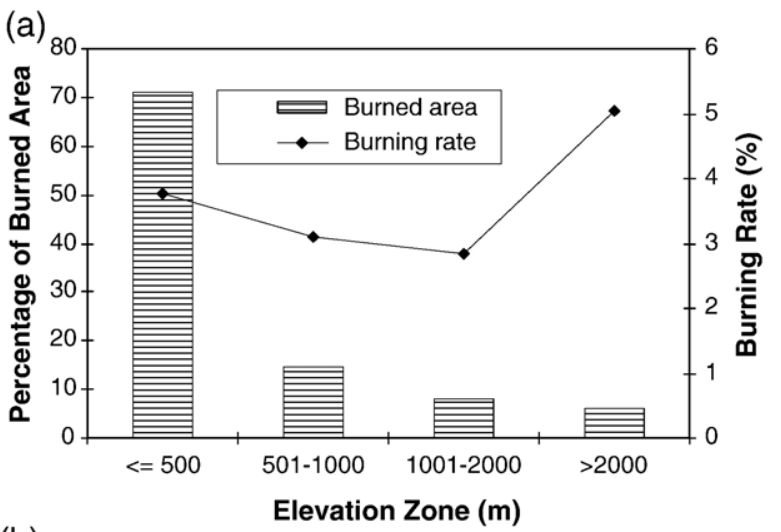

(b)
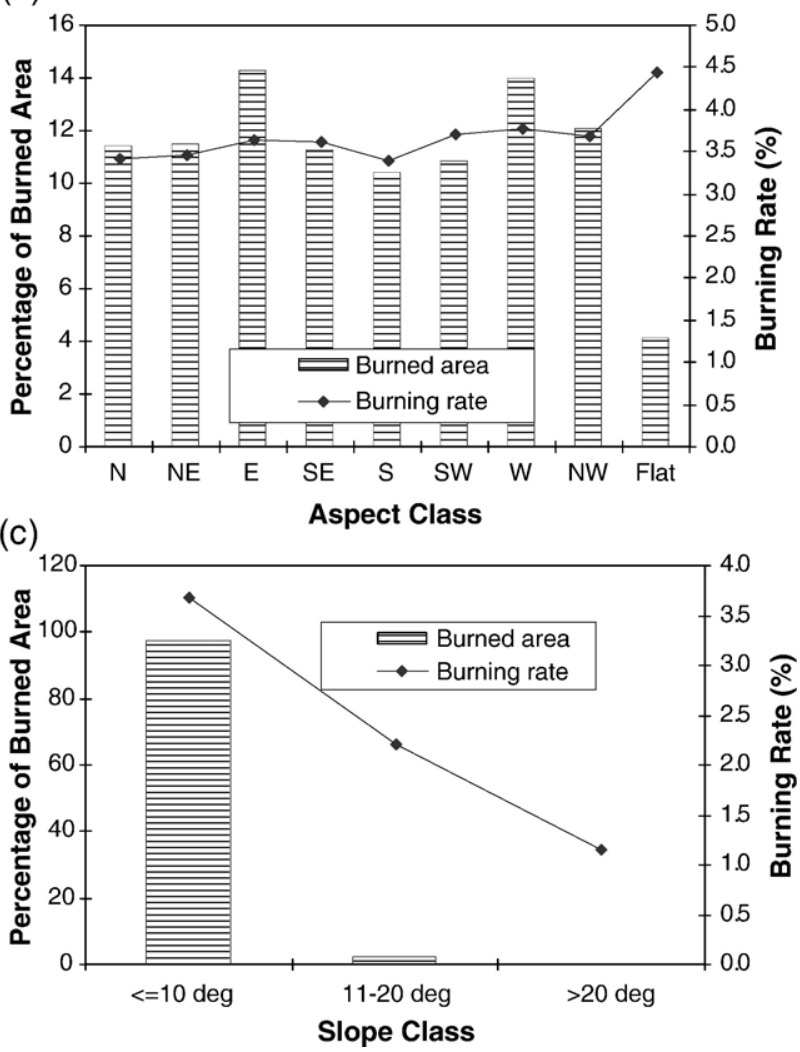

Fig. 4. Percentages of total burned area in different elevation zones (a), aspect (b) and slope (c) classes. Relative burning rates are shown in the curves.

by Canadian provincial forest agencies. See Fig. 1 in Li et al. (2003) for the test results. However, when applying the original algorithm to the entire NA continent, more false fires tended to occur at the edges of thin clouds over warm and bright non-forest land cover types such as open shrub land, sparsely vegetated surface, pasture and range lands (Csiszar et al., 2003). This problem is rooted in the saturation of channel 3 measurements (Csiszar et al., 2003; Li et al., 2001), so the threshold in one of the tests was increased to lessen the problem. Another modification was introduced to more effectively eliminate falsely detected fires due to the sun-glint phenomenon (Li et al., 2003). Both the original and revised algorithm were run daily across the U.S. and Canada throughout the 2000 fire season when many large fires occurred in the Rocky Mountain states ( $\mathrm{Li}$ et al., 2003). In comparison with the in-situ measurements by the forest agencies, both the original and modified algorithms capture most of the real fires, but the modified algorithm eliminates many false fires, especially in southern U.S. (Li et al., 2003). Li et al. (2003) conducted an evaluation study of the algorithms for fire detection and mapping across NA from AVHRR data using detailed fire polygon data obtained from many fires in the Rocky mountain states in U.S. in 2000.

The quality of the burned area data generated by the HANDS method (Fraser et al., 2000) was assessed using the wildfire burned area point dataset of the National Fire Occurrence Database (NFOD: http://www.fs.fed.us/fire/fuelman) maintained by the Fire Science Laboratory, the Rocky Mountain Research Station, and the U.S. Forest Service for the period of May through October in 1996. A total of $11,473 \mathrm{~km}^{2}$ burned area was mapped using the AVHRR, of which $79 \%$ were confirmed by the NFOD and the remaining 21\% represents the upper limit of the commission error (Table 1). It is noteworthy that some real fires, especially the small ones, may be missed by human observers. In terms of the number of fires, $73 \%$ of fires detected by the AVHRR were matched with the NFOD database due to different grouping of fire events. The commission error in fire number is thus up to $27 \%$. Out of the 72 fires reported in the NFOD database, $84 \%$ were correctly mapped and $16 \%$ was omitted (omission error) (Table 1). Fig. 1 shows a scatter plot comparing individual fires from the NFOD and AVHRR. There is a reasonable agreement with the correlation coefficient equal to 0.87 . Better agreement is found for large fires. Note that both the satellite and surface observations suffer from significant uncertainties, due in part to fragmentation of inhomogeneous burning (Fraser et al., 2004). In addition, because of an effect due to the orbital drift of satellite during the 12 years, varying sampling of the diurnal cycle of fire activity may cause potential variations in the hotspots detected with the active fire detection algorithm, and thus may result in variation in the mapping of burned area with the HANDS.

\section{Results}

The fires derived from the AVHRR data are presented and analyzed in terms of (1) inter-annual variation across the 12 years (1989-2000) and the fire season (May through October), (2) three topographic factors (elevation zones, aspect classes and slope classes), (3) 4 major forest types, (4) burn reoccurrence during the 12 year period, and (5) different levels of eco-regions.

The spatial distribution and temporal variation of mapped burned areas varied greatly over North America between 19892000 (Fig. 2). Note that the points shown on the maps are larger than actual fire size to improve visibility. Figs. 2a and 3a show that major burned areas are distributed throughout boreal forests in Canada and Alaska, followed by southeast and southwest U.S. Over half of the burned areas were in the boreal forests of Canada and Alaskan polar eco-domain. The burned areas also fluctuated drastically from one year to another (Fig. 3a). 1995 and 1989 are the two most active years of burning with a total area of $56,840 \mathrm{~km}^{2}$ burned in 1989 , and $63,707 \mathrm{~km}^{2}$ in 1995 . By contrast, only $7000 \mathrm{~km}^{2}$ was burned in 

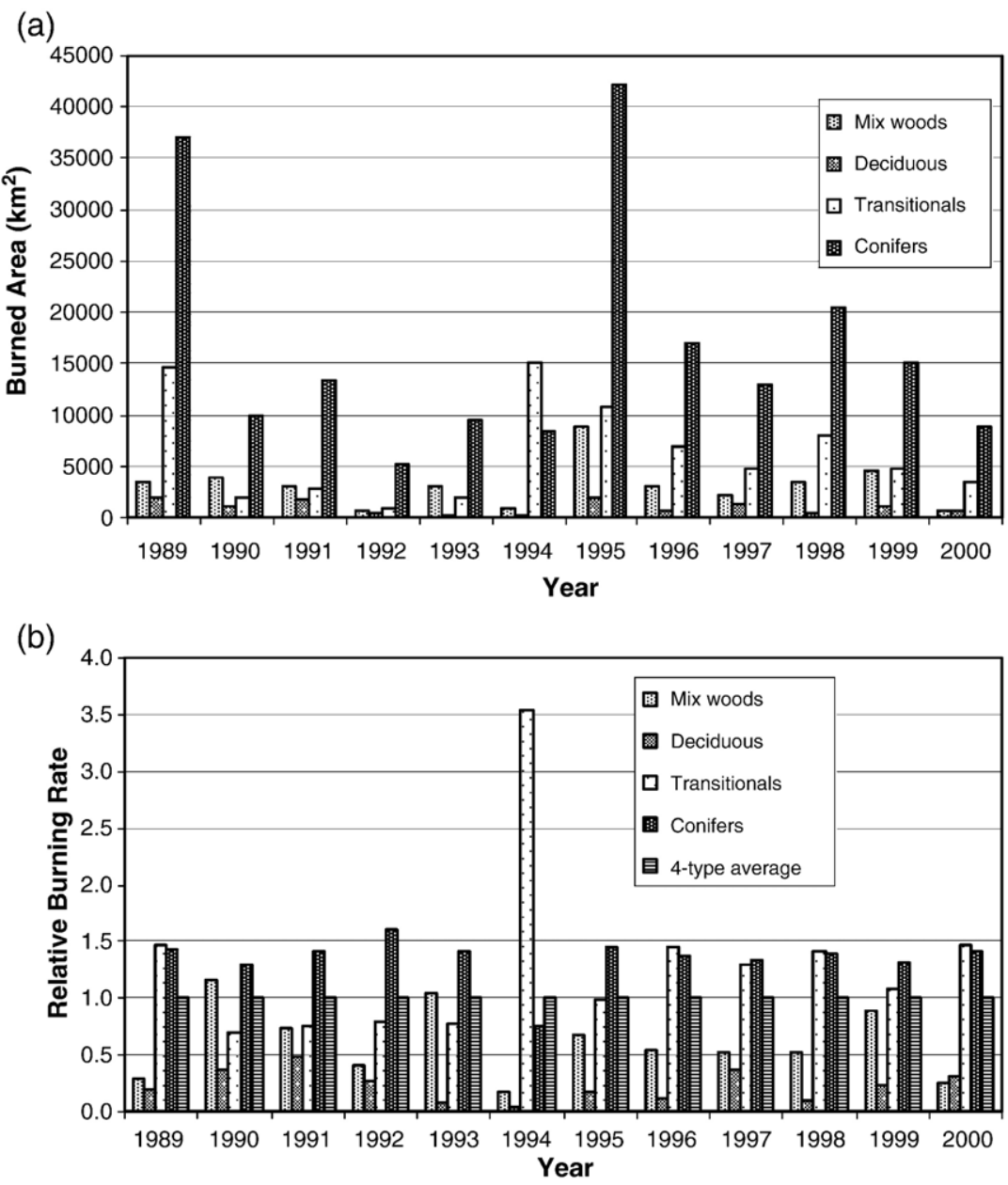

Fig. 5. Annual burned area (a) and relative burning rate (b) distributions of all fires occurring in NA, differentiated according to four forest types.

1992. This finding is consistent with the Canadian fire statistics (Amiro et al., 2001; Stocks \& Simard, 1993; Weber \& Stocks, 1998). Fire occurrence in Canada showed a general increasing trend during the last three decades, with the most dramatic increase observed in the 1980s and 1990s when big fires occurred in western and central Canada. The top two most active fire years were in 1989 and 1995.

The monthly variation of burned areas for the 12 years over NA is shown in Figs. $2 b$ and $3 b$. Of the 6 months, July, June, then August were the most active burning months (33.6\%, 28.8\%, and $22.7 \%$ of burning), while the minimum burning occurred in September $(2.6 \%)$. Further examination of the burn scar areas in the three eco-domains (Fig. 3) reveals that major burnings happened in boreal forests in Canada (polar eco-region), followed by western U.S. mountain areas (dry), but for the September and October, major burnings occurred in southeastern U.S.

The spatial and temporal variation in fire activity is mainly influenced by climate (http://www.cdc.noaa.gov/cdc/data.ncep. reanalysis.derived.html), fuel types, and lightning. High temperature and strong convection, which induces lightning, are two major weather factors causing active fires in the summer season. Relative humidity $(\mathrm{RH})$ is another important factor and is lowest in July over the boreal forest area in Canada and Alaska and in southwestern U.S. Over the southeastern U.S., the lowest monthly mean RH occurs in October. Flannigan and Wotton (1991) found a positive correlation between the number of fires and the number of lightning hits. In NA, most lightning events occur in summer, and the seasonal pattern of lightning is consistent with both the number and extent of forest fires, especially over the boreal forests in Canada (Wierzchowski et al., 2002) and Alaska (Kasischke et al., 2002). Although lightning-ignited forest fires account for only 35\% of fires in Canada, they are responsible for $85 \%$ of the burned area, as the majority of human-induced fires are suppressed at an early stage. Most of the lightning strikes took place in July and June (Wierzchowski et al., 2002) corresponding to the peak of a burning season.

Fig. 4 shows the burn scar distributions over 4 elevation zones, 9 aspect classes, and 3 slope classes. In Fig. 4, the percentage of burned area (\%) for the different elevation zones, aspect classes, and slope classes is defined as a ratio of burned area in a zone or a class to total burned area. The vast majority of forested area has a low elevation $(\leq 500 \mathrm{~m})$ with gentle slopes $\left(\leq 10^{\circ}\right)$, so the majority of burn scars are situated here. Given the variable forest areas in different categories under study, a relative burning rate was derived as the ratio of burned area over the total forest area of the elevation zone. The relative burning rate is plotted in Fig. 4a showing the highest value in elevations greater than $2000 \mathrm{~m}$, and 
Table 2

Areas $\left(\mathrm{km}^{2}\right)$ burned multiple times during the 12 years (1989-2000) over the three eco-domains

\begin{tabular}{lrllcl}
\hline Eco-domain & 1-burn & 2-burn & 3-burn & 4-burn & $\geq 2$ burn(\%) \\
\hline Polar & 237,269 & 5918 & 417 & 21 & 2.61 \\
Humid temperate & 30,305 & 1303 & 138 & 21 & 4.60 \\
Dry & 33,334 & 2180 & 242 & 62 & 6.94 \\
Sum & 300,908 & 9401 & 797 & 104 & 3.31 \\
\hline
\end{tabular}

the lowest value in elevations between $1000-2000 \mathrm{~m}$. It is unclear whether the trend stems from a statistical sampling error or has a real physical cause. There is no clear dependence on the aspect of a slope both in terms of absolute burned area or the relative burning rate (Fig. 4b) although aspect has been considered as a factor in rating fire risk at local scales (Chuvieco \& Congalton, 1989). Note that more than $95 \%$ of the land in NA possesses gentle to flat slopes, which explains why the vast majority of fires occurred in regions with slopes less than $10^{\circ}$ (Fig. 4c). We further consider the three eco-domains separately (not shown). Over the polar eco-domain, the largest proportion of burns occurred in the lower two elevation zones $(<1000 \mathrm{~m})$ with gentle slopes $\left(\leq 10^{\circ}\right)$. In the higher elevations and on steeper slopes, the poor soil and moisture conditions result in fewer fuels and thus limit fire ignition and spread (Rollins et al., 2002). Brown et al. (2001) also found that lower elevation stands have more frequent burning than higher elevation stands.

The proportions of burn scars were also analyzed with respect to four dominant forest types: mixed woods, deciduous, tran-

Table 3

Areas $\left(\mathrm{km}^{2}\right)$ burned multiple times during the 12 years (1989-2000) over the 24 eco-divisions

\begin{tabular}{lrrrc}
\hline Eco-division & 1-burn & 2-burn & 3-burn & 4-burn \\
\hline Icecap & 0 & 0 & 0 & 0 \\
Tundra & 1860 & 37 & 0 & 0 \\
Tundra mountains & 189 & 0 & 6 & 0 \\
Subarctic & 211,603 & 5509 & 400 & 21 \\
Subarctic mountains & 23,617 & 372 & 11 & 0 \\
Warm continental & 1048 & 42 & 21 & 12 \\
Warm contonental mountains & 1695 & 70 & 12 & 1 \\
Hot continental & 1344 & 29 & 8 & 3 \\
Hot continental mountains & 253 & 5 & 2 & 0 \\
Subtropical & 14,502 & 393 & 37 & 2 \\
Subtropical mountains & 412 & 6 & 2 & 0 \\
Marine & 144 & 1 & 1 & 0 \\
Mountains & 1833 & 154 & 18 & 1 \\
Prairie & 1076 & 164 & 16 & 0 \\
Mediterranean & 1651 & 85 & 5 & 0 \\
Mediterranean mountains & 6347 & 354 & 16 & 2 \\
Tropical/subtropical steppe & 3883 & 397 & 29 & 1 \\
Tropical/subtropical steppe mountains & 3367 & 238 & 9 & 0 \\
Tropical/subtropical desert & 2014 & 221 & 22 & 5 \\
Temperature steppe & 1357 & 275 & 75 & 35 \\
Temperature steppe mountains & 19,454 & 787 & 76 & 19 \\
Temperature desert & 2542 & 199 & 21 & 0 \\
Temperature desert mountains & 717 & 63 & 10 & 2 \\
Savanna & 50 & 1 & 0 & 0 \\
Total & 300,958 & 9402 & 797 & 104 \\
\hline & & & & \\
\hline
\end{tabular}
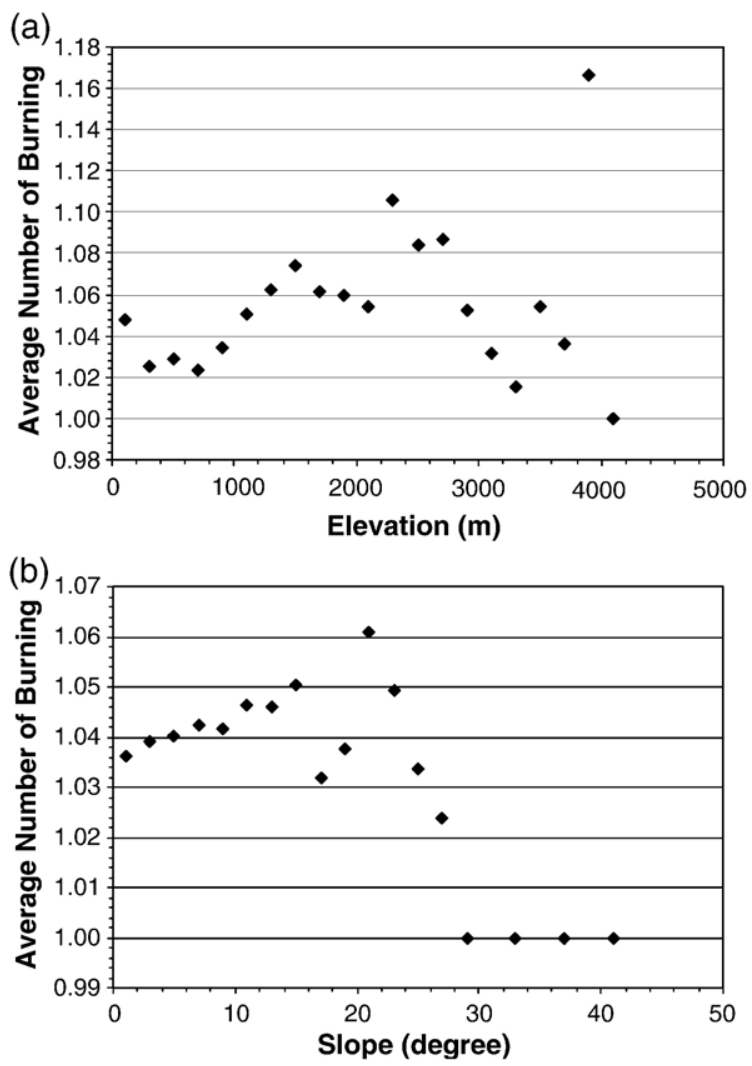

Fig. 6. Average number of single and multi-burning events with respect to elevation (a) and slope (b) during the 12 years.

sitional and coniferous forests. Fig. 5 shows the 12-year burn scar distribution over the four forest types underlying the 3 ecodomains in terms of both burned area (5a) and burning rate (5b). The percentage of burn scars for the four types are as follows: $20.06 \%$ for mixed woods, $17.14 \%$ for deciduous forests, $17.35 \%$ for transitional forests, and $45.46 \%$ for coniferous forests. Similar to the proportion of the forested areas, the majority of burns in NA occurred in coniferous forests (Fig. 5a). The relative burning rate seems to be similar for transitional and coniferous forests after 1996, but before 1996, the rate was higher for conifer forests. The highest burning rate was found for the transitional forest type in 1994.

The statistics of fire reoccurrence differentiated by the ecoregion and eco-divisions are given in Tables 2 and 3 respectively. Areas burned at least twice during the 12 years are only $3.3 \%$ of the total burn area. The absolute and relative values of areas burned at least twice during the 12 years are significantly different across the three eco-domains. In the polar eco-domain, the total area burned at least twice has the maximum occurrence in absolute value but the relative value is minimal among the three eco-domains. The maximum relative occurrence is associated with the dry eco-domain in the western U.S. (about 7\%). This may be due to the complex terrain, which includes areas with large variability in elevation and slope associated with the Sierra Nevada ranges and the Rocky Mountains. Over a terrain region, the burning field is more likely to be patchy, leaving pockets of unburned islands susceptible to future burning. Most areas 
burned at least twice are concentrated over the subarctic ecodivision (with over half of the total areas burned at least twice during the 12 years), followed by the temperate steppe mountains eco-division although the latter only has $8 \%$ of total areas burned at least twice during the 12 years.

Fig. 6 shows the variations of the average number of fire reoccurrence with elevation and slope. The higher elevation zone $(>1500 \mathrm{~m})$ and steeper slopes $\left(>15^{\circ}\right)$ tend to have a higher frequency of multi-burning events, until about $2500 \mathrm{~m}$ elevation and $24^{\circ}$ slope where the tendency of multiple burns starts dropping for very high elevation $(>2500 \mathrm{~m})$ and very steep slopes $\left(>24^{\circ}\right)$ due to a lack of fuels. Rollins et al. (2002) found a similar relation for fire occurrence in two large Rocky Mountain (U.S.) wilderness areas. This kind of result can help interpret forest cover dynamics, especially for those areas where multiburning happened in the 12 years.

\section{Concluding remarks}

In this study, we processed a large volume of daily AVHRR data acquired by NOAA-11 and NOAA-14 satellite platforms for mapping burn scars across the boreal and temperate forests in NA over a 12-year period (1989-2000). The data were first geocoded and composited using the Geocomp-N system (Cihlar et al., 2002). An active fire detection algorithm (Li et al., 2003, 2000a) and a burn scar mapping algorithm (Fraser et al., 2000) were applied to generate daily fire hotspots and to map burned areas across NA. Since the algorithms are most reliable for forested ecosystems, only the results obtained for boreal and temperate forests in the U.S. and Canada are presented and discussed here. Both algorithms were designed originally for application across the Canadian boreal forests using NOAA-14/ AVHRR data. With some minor modifications, they were proven to be effective for application with the NOAA-11 data as well over both boreal and temperate forests. A portion of the 1996 burned area in the U.S. was used to validate the product using the National Fire Occurrence Database. Both algorithms were proven to be suitable for application over forest-covered regions in NA where large, persistent fires that account for the bulk of emissions in greenhouse gases and aerosol particulates usually take place.

The results show three fire bands in NA: boreal forests in Canada and Alaska, and temperate forests in the southeast U.S. and in the southwest U.S., with the majority of burning occurring in July and June, and minor fires occurring in September. The majority of fires occurred in the low elevation zone $(<500 \mathrm{~m})$ and in areas with gentle slopes $\left(<10^{\circ}\right)$, except in the dry ecodomain where more fires occurred in the high elevation zone ( $>2000 \mathrm{~m})$. No significant difference was found in fire occurrence with respect to the aspect of mountain slopes. Most fires were found in the polar eco-domain, over the subarctic ecodivision, and in the taiga (boreal forests), forest-tundras and open woodlands eco-provinces in the boreal forests of Canada. The majority of areas burned at least twice were found in the boreal forests of Canada, but the maximum relative value (Table 2) is over the dry eco-domain in the southwestern U.S. The tendency for multiple burns to occur increases with eleva- tion and slope until about $2500 \mathrm{~m}$ elevation and $24^{\circ}$ slope, and decreases thereafter. These findings might be essential to understand the relationships between biomass burning and emissions and to verify carbon-cycle modeling results and finally to investigate whether different forest types serve as a sink or source over NA in the global carbon cycle. In addition, the results derived from this study might be useful to understand the global carbon cycling and fire emission such as PM2.5 and PM10. For example, a possible implication of the results from this study can help understand the U.S. EPA's National Emission Inventory (NEI) (http://capita.wustl.edu/NAMEN/EPA_NEI.htm) because the inter-annual variability of the amount of some emission/ pollutant species in the NEI is consistent with that of burned areas mapped in this study.

Further and more detailed validation is warranted over different geographic regions, especially in southern U.S. where few ground observations are available. For non-forested ecosystems such as shrubland and grassland, satellite remote sensing suffers from some major inherent difficulties due to the substantial contribution of solar reflection and channel saturation (Csiszar et al., 2003; Li et al., 2001). There is a general lack of spatial fire data over non-forest ecosystems, which are essential for developing and validating fire algorithms. Fortunately, the modern MODIS sensor can overcome, to a certain degree, some of the inherent difficulties. This is because the MODIS sensor has two 4- $\mu \mathrm{m}$ channels (numbered 21 and 22) that are much less contaminated by solar reflection (Kaufman et al., 1998) and have a higher saturation for fire detection (Ch21 saturates at nearly $500 \mathrm{~K}$ and $\mathrm{Ch} 22$ at $331 \mathrm{~K}$ ). In addition, the MODIS $11-\mu \mathrm{m}$ channel (Ch31) that was often used in fire detection algorithms also has a higher saturation point of $400 \mathrm{~K}$ (Justice et al., 2002).

\section{Acknowledgements}

This study was supported by research grants from NASA and NOAA.

The NOAA/AVHRR data used in this analysis were received from the Canada Center for Remote Sensing or downloaded from the NOAA/SAA database (currently renamed as NOAA/ CLASS database).

\section{References}

Agee, J. K. (1993). Fire ecology of Pacific Northwest forests. Covelo, California, USA: Island Press.

Amiro, B. D., Stocks, B. J., Alexander, M. E., Flannigan, M. D., \& Wotton, B. M. (2001). Fire, climate change, carbon and fuel management in the Canadian boreal forest. International Journal of Wildland Fire, 10, 405-413.

Bailey, R. G. (1998). Ecoregions: The Ecosystem Geography of the Oceans and Continents. New York: Springer-Verlag. 192 pp.

Beringer, J., Hutley, L. B., Tapper, N. J., Coutts, A., Kerley, A., \& O’Grady, A. P. (2003). Fire impacts on surface heat, moisture and carbon fluxes from a tropical savanna in northern Australia. International Journal of Wildland Fire, 12, 333-340.

Bowman, D. M. J. S., Zhang, Y., Walsh, A., \& Williams, R. J. (2003). Experimental comparison of four remote sensing techniques to map tropical savanna fire-scars using Landsat-TM imagery. International Journal of Wildland Fire, 12, 341-348. 
Brivio, P. A., Maggi, M., Binaghi, E., \& Gallo, I. (2003). Mapping burned surfaces in sub-Saharan Africa based on multi-temporal neural classification. International Journal of Remote Sensing, 24, 4003-4018.

Brown, A. A., \& Davis, K. P. (1973). Forest Fire: Control and use. New York: McGraw-Hill. 686 pp.

Brown, P. M., Kaye, M. W., Huckaby, L. S., \& Baisan, C. H. (2001). Fire history along environmental gradients in the Sacramento Mountains, New Mexico: Influences of local patterns and regional processes. Ecoscience, 8, 115-126.

Chuvieco, E., \& Congalton, R. G. (1989). Application of remote sensing and geographic information system to forest fire hazard mapping. Remote Sensing of Environment, 29, 147-159.

Cihlar, J., Chen, J., Li, Z., Latifovic, R., Fedosejevs, G., Adair, M., et al. (2002). GeoComp-N, An advanced system for the processing of coarse and medium resolution satellite data. Part 2: Biophysical products for northern ecosystems. Canadian Journal of Remote Sensing, 28, 21-44.

Csiszar, I., Abdelgadir, A., Li, Z., Jin, J., Fraser, R., \& Hao, W. (2003). Interannual changes of active fire detectability in North America from longterm records of the Advanced Very High Resolution Radiometer. Journal of Geophysical Research, 108(D2), 4075. doi:10.1029/2001JD001373

Dwyer, E., Pereira, J. M. C., Grégoire, J. -M., \& DaCamara, C. C. (1999). Characterization of the spatio-temporal patterns of global fire activity using satellite imagery for the period April 1992 to March 1993. Journal of Biogeography, 27, 57-69.

Fisher, R., Vigilante, T., Yates, C., \& Russell-Smith, J. (2003). Patterns of landscape fire and predicted vegetation response in the North Kimberley region of Western Austrialia. International Journal of Wildland Fire, 12, 369-379.

Flannigan, M. D., \& Vonder Haar, T. H. (1986). Forest fire monitoring using NOAA satellite AVHRR. Canadian Journal of Forest Research, 16, 975-982.

Flannigan, M. D., \& Wotton, B. M. (1991). Lightning-ignited forest fires in northwestern Ontario. Canadian Journal of Forest Research, 21, $277-287$.

Fraser, R. H., Hall, R. J., Landry, R., Landry, T., Lynham, T., Raymond, D., et al. (2004). Validation and calibration of Canada-wide coarse-resolution satellite burned maps. Photogrammetric Engineering and Remote Sensing, 70, 451-460.

Fraser, R., \& Li, Z. (2002). Estimating fire-related parameters in the boreal forest using SPOT VEGETATION. Remote Sensing of Environment, 82, 95-110.

Fraser, R. H., Li, Z., \& Cihlar, J. (2000). Hotspot and NDVI differencing synergy (HANDS): A new technique for burned area mapping. Remote Sensing of Environment, 74, 362-376.

French, N. H., Kasischke, E. S., Johnson, R. D., Bourgeau-chavez, L. L., Frick, A. F., \& Ustin, S. (1996). Estimating fire-related carbon flux in Alaskan boreal forests using multisensor remote-sensing data. In J. S. Levine (Ed.), Biomass Burning (pp. 278-295). Cambridge: MIT Press

Fung, I. (1996). The global carbon cycle and atmospheric record: "The problem definition”. In M. J. Apps \& D.T. Price (Eds.), Forest Ecosystems, Forest Management and the Global Carbon Cycle (pp. 25-34).

Fuquay, D. M., Bauhman, R. G., \& Latham, D. J. (1979). A model for predicting lightning fire ignition in wildland fuels. RP-INT-217 Ogden, Utah, USA: USDA Forest Service, Intermountain Forest and Range Experiment Station.

Hao, W. M., Ward, D. E., Olbu, G., \& Baker, S. P. (1996). Emissions of $\mathrm{CO}_{2}$, $\mathrm{CO}$, and hydrocarbons from fires in diverse African savanna ecosystems. Journal of Geophysical Research, 101(D19), 23577-23584.

Isaev, A. S., Korovin, G. N., Bartalev, S. A., Ershov, D. V., Janetos, A., Kasischke, E. S., et al. (2002). Using Remote sensing to assess Russian forest fire carbon emissions. Climatic Change, 55, 235-249.

Justice, C. O., Giglio, L., Korontzi, S., Owens, J., Morisette, J. T., Roy, D., et al. (2002). The MODIS fire products. Remote Sensing of Environment, 83, 244-262.

Justice, C. O., Kendall, J. D., Dowty, P. R., \& Scholes, R. J. (1996). Satellite remote sensing of fires during the SAFARI campaign using NOAA advanced very high resolution radiometer data. Journal of Geophysical Research, 101(23), 823-851 (863).

Justice, C. O., Smith, R., Gill, A. M., \& Csiszar, I. (2003). A review of current space-based fore monitoring in Australia and the GOFC/GOLD program for international coordination. International Journal of Wildland Fire, 12, $247-258$.
Kasischke, E. S., \& Bruhwiler, L. P. (2003). Emissions of carbon dioxide, carbon monoxide, and methane from boreal forest fires in 1998. Journal of Geophysical Research, 108(D1), 8146. doi:10.1029/2001JD000461

Kasischke, E. S., Williams, D., \& Barry, D. (2002). Analysis of the patterns of large fires in the boreal forest region of Alaska. International Journal of Wildland Fire, 11, 131-144.

Kaufman, Y. J., Ichoku, C., Giglio, L., Korontzi, S., Chu, D. A., Hao, W. M., et al. (2003). Fire and smoke observed from the Earth Observing System MODIS instrument-products, validation, and operational use. International Journal of Remote Sensing, 24(8), 1765-1781.

Kaufman, Y. J., Justice, C. O., Flynn, L. P., Kendall, J. D., Prins, E. M., Giglio, L., et al. (1998). Potential global fire monitoring from EOS-MODIS. Journal of Geophysical Research-Atmospheres, 103, 32215-32238.

Kaufman, Y. J., Setzer, A., Justice, C., Ticker, C. J., \& Fung, I. (1990). Remote sensing of biomass burning in the tropics. In J. G. Goldammer (Ed.), Fires in the Tropical Biota, Ecosystem Processes and Global Changes (pp. 371-399).

Kaufman, Y. J., Tanre, D., \& Ward, D. E. (1994). Remote sensing of biomass burning in the Amazon. Remote Sensing Reviews, 10, 51-90.

Kaufman, Y. J., Tucker, C. J., \& Fung, I. (1990). Remote sensing of biomass burning in the tropics. Journal of Geophysical Research, 95, 9927-9939.

Kurz, W. A., \& Apps, M. J. (1996). Retrospective assessment of carbon flows in Canadian boreal forests. In M. J. Apps \& D. T. Price (Eds.), Forest Ecosystems, Forest Management and the Global Carbon Cycle (pp. 173-182)

Li, Z., Cihlar, J., Moreau, L., Huang, F., \& Lee, B. (1997). Monitoring fire activities in the boreal ecosystem. Journal of Geophysical Research, 102, 29611-29624.

Li, Z., Fraser, R., Jin, J., Abuelgasim, A. A., Csiszar, I., Gong, P., et al. (2003). Evaluation of algorithms for fire detection and mapping across North America from satellite. Journal of Geophysical Research, 108(D2), 4076. doi:10.1029/2001JD001377

Li, Z., Jin, . J., Gong, P., \& Pu, R. (2006). Use of satellite remote sensing data for modeling carbon emissions from fires: A perspective in North America. In Qu, et al. (Eds.), Earth Science Satellite Remote Sensing (pp. 337-356). Springer-Verlag (Chapter 18).

Li, Z., Kaufman, Y. J., Ithoku, C., Fraser, R., Trishchenko, A., Giglio, L., et al. (2001). A review of AVHRR-based active fire detection algorithms: Principles, limitations, and recommendations. In F. Ahern, J. G. Goldammer, \& C. Justice (Eds.), Global and Regional Vegetation Fire Monitoring from Space, Planning and Coordinated International Effort (pp. 199-225).

Li, Z., Nadon, S., \& Cihlar, J. (2000). Satellite detection of Canadian boreal forest fires: Development and application of an algorithm. International Journal of Remote Sensing, 21, 3057-3069.

Li, Z., Nadon, S., Cihlar, J., \& Stocks, B. J. (2000). Satellite mapping of Canadian boreal forest fires: Evaluation and comparison of algorithms. International Journal of Remote Sensing, 21, 3071-3082.

Liu, Y. (2004). Variability of wildland fire emissions across the contiguous United States. Atmospheric Environment, 38, 3489-3499.

Loveland, T. R., Reed, B. C., Brown, J. F., Ohlen, D. O., Zhu, J., Yang, L., et al. (2000). Development of a Global Land Cover Characteristics Database and IGBP DISCover from 1-km AVHRR Data. International Journal of Remote Sensing, 21, 1303-1330.

Morisette, J. T., Giglio, L., Csiszar, I., \& Justice, C. O. (2005). Validation of the MODIS active fire product over Southern Africa with ASTER data. International Journal of Remote Sensing, 26, 4239-4264.

Prins, E. M., \& Menzel, W. P. (1990). Geostationary satellite detection of biomass burning in South America. International Journal of Remote Sensing, 13, 2783-2799.

Pu, R., Gong, P., Li, Z., \& Scarborough, J. (2004). A dynamic algorithm for wild land burned scar detection using NOAA AVHRR data. International Journal of Wildland Fire, 13, 275-285.

Qi, Y., \& Gong, P. (1996). Metabolic and phenological response of vegetation to temperature gradient: evidence derived from AVHRR data. Geographic Information Sciences, 2, 64-72.

Rao, C. R. N., \& Chen, J. (1996). Post-launch calibration of the visible and nearinfrared channels of the Advanced Very High Resolution Radiometer on NOAA-14 spacecraft. International Journal of Remote Sensing, 17, 2743-2747. 
Rollins, M. G., Morgan, P., \& Swetnam, T. (2002). Landscape-scale controls over 20th century fire occurrence in two large Rocky Mountain (USA) wilderness areas. Landscape Ecology, 17, 539-557.

Stocks, B. J., \& Simard, A. J. (1993). Forest fire management in Canada. Disaster Management, 5, 1-7.

Tans, P. P., Fung, I. Y., \& Takahishi, T. (1990). Observational constraints on the global CO2 budget. Science, 247, 1431-1438.

Ward, D. E., Hao, W. M., Susott, R. A., Babbitt, R. E., Shea, R. W., Kauffman, J. B., et al. (1996). Effect of fuel composition on combustion efficiency and emission factors for Aferican savanna ecosystems. Journal of Geophysical Research, 101(D19), 23569-23576.
Waring, R. H., \& Running, S. W. (1998). Forest Ecosystems: Analysis at Multiple Scales. San Diego, California, USA: Academic Press.

Weber, G., \& Stocks, B. (1998). Forest fires and sustainability in the boreal forest of Canada. Ambio, 27(7), 545-550.

Westerling, A. L., Gershunov, A., Brown, T. J., Cayan, D. R., \& Dettinger, M. D. (2003). Climate and wildfire in the western United States. Bulletin of the American Meteorological Society, 84, 595-604.

Wierzchowski, J., Heathcott, M., \& Flannigan, M. D. (2002). Lightning and lightning fire, central cordillera, Canada. International Journal of Wildland Fire, 11, 41-51. 